\title{
REGISTRO DO PATRIMÔNIO HISTÓRICO RURAL A PARTIR DA HISTÓRIA ORAL
}

\author{
REGISTRO DEL PATRIMONIO HISTÓRICO \\ RURAL A PARTIR DE LA HISTORIA ORAL
}

\author{
Luzia Sigoli Fernandes Costa - luziasigoli@gmail.com \\ Doutora em Ciência da Informação pela Universidade Estadual \\ Paulista Júlio de Mesquita Filho (UNESP/Marília). Professora da \\ Universidade Federal de São Carlos (UFSCar). \\ Luciana de Souza Gracioso - lugracioso@yahoo.com.br \\ Doutora em Ciência da Informação pelo Instituto Brasileiro de \\ Informação em Ciência e Tecnologia e Universidade Federal \\ Fluminense (IBICT/UFF). Professora da Universidade Federal de \\ São Carlos (UFSCar).
}

\begin{abstract}
RESUMO
Introdução: Descreve a atividade desenvolvida em fazenda histórica do interior do estado de São Paulo, com o intuito de registrar bens culturais imateriais para fins de documentação e preservação da memória social rural.

Objetivo: Coletar história oral sobre os modos de vida das fazendas históricas do interior de São Paulo com o intuito de preservar e divulgar este patrimônio imaterial.

Metodologia: Para coleta de dados, foram desenvolvidas entrevistas presenciais, a partir da abordagem metodológica de história oral, com apoio teórico pautado em S. Ranganathan, com dez ex moradores, funcionários e proprietários da Fazenda Santa Maria do Monjolinho.

Resultados: As entrevistas foram tabuladas e analisadas e os resultados foram utilizados para a produção de um documentário sobre os modos de vida da rural.

Conclusão: Conclui-se que foi possível promover a sensibilização das comunidades locais para a valorização de seu próprio patrimônio histórico, estimular a formação de consciência crítica e desenvolvimento de atitudes favoráveis à valorização e preservação do patrimônio cultural, e confirmar que ações de coleta, registro e disseminação do patrimônio histórico podem sensibilizar também, a médio prazo, o poder público para a incorporação de políticas voltadas à proteção do patrimônio cultural.
\end{abstract}

Palavras-chave: Patrimônio histórico. Fazenda histórica. História oral. 


\section{INTRODUÇÃO}

Nas últimas décadas, no Brasil, tem crescido o processo de tomada de consciência por parte do poder público, da iniciativa privada e da sociedade civil, empoderada pelas redes e movimentos sociais, da necessidade de se preservar os bens expressivos da diversidade cultural do país. Esse processo vem contribuindo para a construção da identidade cultural despertando o sentimento de pertencimento e de cidadania em diferentes comunidades e, em especial, nas regiões do interior do Estado de São Paulo.

Essa diversidade de bens culturais se, por um lado, representa uma grande potencialidade de pesquisas e ações de políticas públicas, por outro, está permanentemente apresentando muitos desafios para aqueles que enveredam pelos estudos em busca de descoberta, identificação, caracterização, análise e descrição desses bens, de tal forma, que possam resultar em produções e serviços de informação para a sociedade.

Dentre os principais desafios, pode ser mencionado o fato de que muitos dos testemunhos históricos que permitiriam a identificação e a análise do patrimônio cultural se perderam ou estão se perdendo. Portanto, se faz urgente o aperfeiçoamento de metodologias para registrar, organizar e tornar acessível o patrimônio que ainda resta. Nesse caso, para que a informação possa cumprir o seu papel na sociedade, é preciso, na medida do possível, se fazer a recuperação ou a re-significação de fatos, acontecimentos, objetos e lugares, dentre outros elementos, que permitam identificar e caracterizar os patrimônios imaterial e material, construído e natural, existentes concretamente e daqueles guardados na memória e práticas de determinadas comunidades.

Nesse contexto, está em desenvolvimento uma pesquisa ampla e interdisciplinar que objetiva criar e aperfeiçoar instrumentos que possam facilitar as ações de identificar, categorizar, reunir, articular e disponibilizar informações históricas, a partir do patrimônio cultural 
presente nas fazendas de café, surgidas nos séculos XVIII e XIX, no interior do estado de São Paulo, mais especificamente nos "Campos de Araraquara". Para tanto, é necessário estudar aspectos da relação entre os contextos rural e urbano, ou seja, campo e cidade, uma vez que as fazendas de café do interior paulista, não poucas vezes, caracterizam-se como o principal elemento fundador e de desenvolvimento dos núcleos urbanos sob sua influência e vice-versa.

Diante dessa pluralidade cultural, em que ocorre o desenvolvimento econômico e social, torna-se de fundamental importância o levantamento, registro e elaboração de sínteses descritivas e analíticas sobre esse patrimônio. Para tanto, torna-se necessário desenvolver, aprimorar, testar e validar critérios e metodologias consistentes teoricamente para se realizar a caracterização das diferentes tipologias de bens culturais rurais paulistas e do seu conjunto e, ainda, do estabelecimento de diálogo com as instituições culturais metropolitanas. As instituições formais de apoio a pesquisa, educação e cultura representadas pelas bibliotecas, arquivos, museus e centros de memória, em se tratando do interior paulista ainda carecem de organização e acondicionamento adequados de suas coleções e acervos. Esse fato dificulta as pesquisas documentais e, consequentemente, as análises mais aprofundadas sobre os contextos históricos, a partir dos bens culturais.

Para minimizar essa problemática, é preciso, além de reunir elementos que subsidiem a implantação de projetos inovadores é necessário também fortalecer as políticas públicas de incentivo às iniciativas de conservação de acervos e coleções de bens culturais, independentemente se a responsabilidade pela sua guarda esteja no âmbito do público, ou do privado, desde que sejam garantidos o acesso e a apropriação das informações pela sociedade. Dessa forma, deve-se promover não só o acesso, mas também o diálogo e a interoperabilidade entre acervos e coleções de documentos primários, de registros de 
depoimentos, de coleções bibliográficas, iconográficas e museológicas e demais elementos que são afetos a um determinado território.

A preservação, o acesso e o entendimento sobre os bens culturais servem para o reconhecimento das paisagens culturais, do patrimônio arqueológico e do ambiente (natural e antrópico) e de outros lugares de memória que abrigam as edificações históricas, vindo a se constituírem, de fato, como fontes para a pesquisa, o ensino e a cultura. Essas fontes fazem com que se mantenha, ou até amplie, o sentido desses bens culturais para a comunidade local e regional, na medida em que se apresentam como parte do mosaico de uma rede de significados da memória e da história do próprio Estado de São Paulo e, até mesmo, do país.

Para desenvolver, aprimorar, testar e validar os critérios e metodologias para realização de descrição de bens culturais que possam contribuir com a resolução dos problemas de tratamento da informação histórica, anteriormente citados, realizou-se uma atuação intensiva de pesquisa e intervenção na região de São Carlos, por reunir fazendas históricas ${ }^{1}$ bastante significativas, cujos proprietários são sensíveis às questões de preservação. A história da região de São Carlos está totalmente imbricada com as fazendas de café que, além de promoverem o desenvolvimento econômico e social, deram origem a muitas das práticas culturais paulistas, tornando-se, portanto, fortemente representativas da cultura caipira e oferecendo, inclusive, oportunidade de valorização dos conhecimentos tradicionais locais.

Nesse micro universo, representativo das fazendas do interior do Estado de São Paulo, foi escolhida a Fazenda Santa Maria do Monjolinho, situada em São Carlos, pertencente a macro região de Araraquara, como espaço de estudo e aplicação de metodologia de

\footnotetext{
${ }^{1}$ São três fazendas tombadas pelo CONDEPHAAT na região de São Carlos (uma delas tem tombamento nacional). Projetos de pesquisa dessa natureza são importantes para o fomento de políticas preservacionistas, auxiliando os órgãos competentes com dados, informações e conhecimentos acerca do patrimônio cultural rural paulista que poderão subsidiar futuros processos de tombamento.
} 
coleta de dados sobre o patrimônio rural paulista. Foi desenvolvida pesquisa, para identificar o patrimônio cultural deste ambiente, cujo procedimento híbrido de coleta de dados será descrito neste artigo. Um dos desdobramentos desta pesquisa foi a edição de um documentário sobre os modos de vida da fazenda, lançado em 2011, para fins de educação patrimonial e preservação da memória.

\section{O PATRIMÔNIO CULTURAL DA FAZENDA SANTA MARIA DO MONJOLINHO}

A Fazenda Santa Maria do Monjolinho foi aberta em 1850 para o cultivo do café por José Inácio de Camargo Penteado, antes mesmo da constituição do município de São Carlos, em terras pertencentes aos "Campos de Araraquara". A propriedade foi transferida em 1904 para Candido de Souza Campos e sua esposa, Zuleika Malta, e se mantém até hoje nas mãos de seus descendentes, sendo administrada pelo seu neto Décio Malta Campos. A fazenda tem preservado um extraordinário patrimônio arquitetônico composto da casa principal, edificada ainda no século XIX, terreiro de secagem de café, casa de máquina e seus maquinários, tulha, oficina, serraria, senzala, capela, estrebaria, cocheira, casas do capataz e do capitão do mato e a estação de trem. Dos seus 1.500 ha, aproximadamente 320 ha são constituídos de Mata Atlântica, de mananciais e de cerrado, bens naturais esses enriquecedores do seu patrimônio. Destacamos ainda os seus bens móveis bem preservados, como o mobiliário, os utensílios domésticos, os objetos de decoração, a documentação notarial e um valioso acervo fotográfico. Esta fazenda foi reconhecida pelo CONDEPHAT, em 2007, como Patrimônio Histórico do Estado de São Paulo.

\subsection{O acervo documental de impressos e manuscritos da} Fazenda Santa Maria do Monjolinho

Com relação à coleção de material impresso, esta fazenda possui 
um acervo de aproximadamente 2000 livros sobre temáticas bastante diversificadas, agricultura, cafeicultura, pecuária, literatura e outros. Possui, também, um acervo de periódicos com títulos bastante significativos, que circularam entre os anos de 1954 e 1978. Esses periódicos, na sua grande maioria, são especializados em agropecuária, perfazendo um total de, aproximadamente, 4000 exemplares de revista. $O$ acervo possui, também, uma hemeroteca, iconografia impressa, plantas e mapas, álbuns fotográficos, contendo retratos de famílias, de festas, de colheitas, dentre outros assuntos e ainda, muitos cartões de visitas e cartões postais, sem endereçamento.

$\mathrm{O}$ acervo de manuscritos, também, é bastante expressivo. Foram encontrados cartões de apresentação e cartões postais endereçados, cartas de jesuítas, livros contábeis e livros de ponto do período de 1914 a 1917, escrituras de compra e venda (1904 e 1928), receitas e santinhos, em pouca quantidade. Foram encontrados, ainda, cadernos escolares impecáveis com boa caligrafia e desenhos explicativos da matéria estudada, no ano de 1917.

Nesta fazenda, cabe destacar a coleção que pertenceu ao Prof. Dr. Ernesto Souza Campos (1882-1970), cujos dados biográficos merecem ser mencionados. Souza Campos, como é conhecido, formouse engenheiro em 1906 pela Escola Politécnica de São Paulo e médico pela Faculdade de Medicina de São Paulo. Como primeiro aluno dos cursos e pelo reconhecimento dos resultados de seus estudos recebeu como prêmio a oportunidade de estudar nos Estados Unidos, pela Comissão da Rockfeller Foundation (CAMPOS; LEME, 1964; CAMPOS, 1956).

Estudioso, incondicional, Souza Campos conheceu muitas universidades européias e foi motivado a lutar pelo ideal de unir as faculdades existentes em São Paulo, contribuindo, assim, de forma decisiva para a criação da Universidade de São Paulo - USP. Pela sua dedicação acadêmica nos Estados Unidos, obteve da Fundação Rockfeller os recursos para construção do Hospital das Clinicas. No 
interior paulista, iniciou as primeiras Escolas Estaduais, das quais originaram a UNESP. Foi Ministro da Educação e fundou as Universidades Católicas da Bahia, Recife, Paraná e de São Paulo e a do Rio de Janeiro. Ocupou a cadeira no 34 da Academia Paulista de Letras. E dizia "Ciências e Letras não se repelem, antes se atraem, se interpenetram". Fundou o PEN Clube de São Paulo (poetas, ensaístas e novelistas) com atividade exclusiva no campo literário, é uma instituição patrocinada pela UNESCO, com sede em Londres. O PEN de São Paulo surgiu com os inúmeros escritores na tradicional Faculdade de Direito da Universidade de São Paulo.

A vida de Ernesto Souza Campos foi dedicada ao ensino público universitário, criando universidades e institutos de pesquisas, à saúde pública, construindo hospitais, à literatura e à história, escrevendo livros, participando da academia e fundando clube literário.

O acervo bibliográfico que pertenceu a Ernesto Souza Campos, reunido pesquisas, desde a criação da primeira revista médica, e todos seus estudos científicos, foi doado à USP, campus de São Paulo. No entanto, os documentos impressos e manuscritos de seu acervo pessoal, revelando a trajetória de todas as suas realizações como, por exemplo, o esboço ou croqui, feito de próprio punho, expondo as ideias para a criação da primeira Universidade de São Paulo estão preservados e guardados no Instituto Souza Campos, sediado na Fazenda Santa Maria do Monjolinho, em São Carlos.

Existem tantas outras infinidades de riquezas documentais no ambiente desta fazenda que merecem ser conhecidas e compartilhadas. Esforços de muitas instituições, pesquisadores, alunos e setor público têm sido feitos no sentido de identificar e preservar o patrimônio material e imaterial destes espaços que foram formadores de modos de vida de nossa sociedade brasileira. 


\section{INICIATIVAS DE PESQUISAS NAS FAZENDAS HISTÓRICAS DO INTERIOR DE SÃO PAULO}

Várias são as iniciativas em prol da conservação, organização e disponibilização dos acervos da Fazenda Santa Maria do Monjolinho, de modo geral. Além das atividades contínuas de pesquisa, que reúnem pesquisadores das principais universidades do Estado de São Paulo como USP, UFSCAR, UNICAMP e da UNESP, essa fazenda conta com estagiários, do Curso de Biblioteconomia e Ciência da Informação da UFSCar, realizando processo de higienização e de organização prévia das coleções. Incluindo a elaboração "Fichas de Diagnóstico" do estado de conservação acervos do patrimônio material de impressos, manuscritos e iconográfico.

Atualmente, são desenvolvidas várias ações integradas entre as fazendas $e$ as universidades instaladas na região possibilitando, primeiramente, a visibilidade de verdadeiros tesouros, escondidos há séculos nessas fazendas cafeeiras do interior paulista. Estas atividades se caracterizam por uma série de ações que ocorreram de forma intensiva e concentrada em alguns períodos do ano letivo, em que um grupo, de aproximadamente 30 pessoas, composto por pesquisadores, técnicos especializados, alunos de diferentes níveis formação e áreas de conhecimento, os proprietários e trabalhadores da fazenda e pessoas da sociedade civil interessadas na temática que se embrenham de forma articulada para pesquisar e produzir conhecimento como parte de Cursos de Extensão em temáticas como "Patrimônio e Cultura Digital: Processos Multimídias nas Fazendas de Café: História, Arquitetura e Tecnologia", promovido pelo Instituto de Arquitetura e Urbanismo da USP São Carlos, de Atividade Curricular de Integração Ensino, Pesquisa e Extensão (ACIEPE) "Fazendas históricas: descobrindo suas múltiplas dimensões", promovido Departamento de Ciência da Informação da UFSCar e, ainda, como parte das atividades do projeto, PPPP 2007/FAPESP, "Patrimônio Cultural Rural Paulista: espaço privilegiado 
para pesquisa, educação e turismo", coordenado pelo Prof. Dr. Marcos Tognon do Centro de Memória da UNICAMP, no qual muitas das discussões que apresentamos, são estudadas. Outras participações ocorrem a cada oferta, como por exemplo, do Curso de Turismo da UNESP (Campus de Rosana).

Das atividades de campo desenvolvidas pelos diferentes projetos decorrem centenas de registros, iconográfica e audiovisual, destacando a produção de vídeo enfocando a história da fazenda. Registro fotográfico e em vídeo das paisagens, suas edificações (em tomadas internas e externas). Registro da documentação como fotografias, mapas, discos, fitas de pianola, entre outros, gerando uma rica produção bibliográfica, iconográfica, audiovisual que tem ao mesmo tempo o intuito de documentar e registrar as sutilezas históricas e sociais destes ambientes rurais históricos. Essa produção, objetiva também gerar conhecimentos organizados para disponibilização e uso em escolas, prefeituras e comunidade em geral.

Neste cenário, a finalidade do presente artigo é detalhar o resultado de uma pesquisa pontual feita na Fazenda Santa Maria do Monjolinho, que teve como objetivo central o registro das histórias de vida de funcionários proprietários que atuaram na fazenda, como objetivo de recuperar um patrimônio histórico imaterial nacional. Estas histórias apresentam relações diretas com a forma de concebermos o Brasil, atualmente, tanto em seus aspectos culturais, econômicos e de relações interpessoais.

Para tanto foi proposto um método indireto para o desenvolvimento destas entrevistas que se mostrou amplamente satisfatório, tendo sido possível, ao final da pesquisa, promover o seu desdobramento na produção de um documentário sobre os modos de vida da fazenda Santa Maria do Monjolinho, em São Carlos-SP. 


\section{METODOLOGIA DA PESQUISA: A VIDA COTIDIANA COMO PONTO DE PARTIDA}

A atividade de pesquisa desenvolvida junto a Fazenda Santa Maria do Monjolinho trabalha com base empírica, demanda uma ação, a resolução de uma questão coletiva, que diz respeito a demanda pela documentação e preservação das histórias e fazeres da Fazenda. Pesquisadores, estudantes, moradores e trabalhadores da fazenda estão envolvidos de modo participativo com todo o processo. Tem como meta a intervenção, na medida em que poderá desencadear novas diretrizes e políticas públicas locais sobre o patrimônio histórico do interior de São Paulo, constituído nos espaços das fazendas históricas. Esta pesquisa se propôs a estudar e analisar situações específicas no que diz respeito ao contexto de produção, registro e preservação de saberes constituídos no espaço de uma fazenda histórica do interior paulista, portanto, não visa produzir enunciados científicos generalizáveis. Como instrumento de coleta de dados, foram desenvolvidas entrevistas presenciais, a partir da abordagem metodológica de história oral, com ex moradores, funcionários e proprietários da Fazenda Santa Maria do Monjolinho. A história oral é considerada uma metodologia de pesquisa que consiste em realizar entrevistas gravadas com pessoas que podem testemunhar sobre, fatos, acontecimentos, conjunturas, instituições, modos de vida ou sobre outros aspectos da história contemporânea. Começou a ser utilizada nos anos 1950 e desde então tem sido bastante difundida.

A história oral é uma história construída em torno de pessoas. Ela lança a vida para dentro da própria história e isso alarga seu campo de ação. Admite heróis vindos não só dentre os líderes, mas dentre a maioria desconhecida do povo. Estimula professores e alunos a se tornarem companheiros de trabalho. Traz a história para dentro da comunidade e extrai a história de dentro da comunidade. Ajuda os menos privilegiados, e especialmente os idosos, a conquistar dignidade 
e autoconfiança. Propicia o contato - e, pois, a compreensão - entre classes sociais e entre gerações. E para cada um dos historiadores e outros que partilhem das mesmas intenções, ela pode dar um sentimento de pertencer a determinado lugar e a determinada época. Em suma, contribui para formar seres humanos mais completos. Paralelamente, a história oral propõe um desafio aos mitos consagrados da história, ao juízo autoritário inerente a sua tradição. E oferece os meios para uma transformação radical no sentido social da história. (THOMPSON,1992, p. 44).

Por meio da história oral aspectos das experiências vividas, em diferentes circunstâncias, adquirem sentido social. Sendo assim, as narrativas do cotidiano das pessoas comuns se configuram como história e memórias, se traduzem em rememorações que ao recriarem o sentido das lembranças e refazerem os sentidos da experiência através da linguagem. Cada sujeito concebe os fatos e os acontecimentos vividos, em sua trajetória pessoal e social, como uma experiência e saberes comunicáveis pela linguagem. Esses saberes particulares, que circulam nas práticas cotidianas, é um saber-memória que se expressa nas histórias que contamos e que nos foram contadas (CERTEAU, 2009).

Compartilhar memórias é uma forma de construir redes de solidariedade através do exercício de relacionamento, de novos modos de sociabilidade democrática e novas formas de criatividade social. $\mathrm{Na}$ vida cotidiana circula uma pluralidade de significações, interesses e valores que engendra formas afirmativas de emancipação. Diante da crise paradigmática em que vivemos Santos (2000) aponta a necessidade de recuperarmos uma tradição epistemológica marginalizada e desacreditada da modernidade, o conhecimentoemancipação. Esse conhecimento-reconhecimento, Santos (2000) chama de solidariedade que é uma prática de conhecimento que se desdobra numa prática política. A solidariedade como forma de conhecimento engendra práticas emancipatórias, que produzidas nas 
dobras da realidade cotidiana se afirmam no silêncio das vozes caladas que ecoam do passado e recriam o futuro pela produção de novos tempos e sentidos.

Tendo em vista o objetivo maior de produção de documentário sobre as formas de vida da respectiva fazenda, foi delimitado um conjunto de estratégias para condução desta prática de pesquisa, que relatamos a seguir.

Toda a coleta de dados foi feita a partir de uma série de ações in loco que ocorreram de forma intensiva e concentrada em apenas 4 dias com a vista dos pesquisadores na fazenda. O período de realização foi de 9 a 12 de Outubro de 2010 e reuniu uma equipe de aproximadamente 30 (trinta) participantes entre professores, pesquisadores, técnicos especializados e alunos de graduação e pósgraduação. Esta atividade foi realizada de forma articulada entre Universidade de São Paulo (USP), a Universidade Federal de São Carlos (UFSCar) e Universidade de Campinas (UNICAMP), cuja formalização se deu de maneira independente em cada universidade, conforme reflete as responsabilidades assumidas, assim constituídas:

a) USP - Curso de Extensão - Patrimônio e Cultura Digital: Processos Multimídias nas Fazendas de Café: História, Arquitetura e Tecnologia.

b) UFSCar - Atividade Curricular de Integração Ensino, Pesquisa e Extensão (ACIEPE).

c) UNICAMP - Como parte das atividades do projeto, PPPP 2007/FAPESP, "Patrimônio Cultural Rural Paulista: espaço privilegiado para pesquisa, educação e turismo". Neste âmbito houve, também, a participação da UNESP (Campus de Rosana).

Inicialmente, no primeiro dia de pesquisa in loco, foi feita uma explanação de abertura falando sobre os objetivos da atividade e uma 
apresentação dos docentes coordenadores e demais envolvidos. Nesse momento foi feita, também, uma apresentação de Francisco de Carvalho Dias de Andrade - Mestrando em História e orientando pelo Prof. Dr. Marcos Tognon (UNICAMP).

Posteriormente foi dado início ao desenvolvimento de entrevistas com funcionários e outros atores da respectiva fazenda Santa Maria do Monjolinho. Foram realizadas 10 (dez) entrevistas com duração entre 40 a 60 minutos cada. Os entrevistados foram, na sua maioria, empregados da fazenda e, também, os proprietários e seus familiares. As entrevistas foram gravadas e para tanto foram montados três ambientes, na própria fazenda, que serviram de estúdio para as gravações. Portanto, houve capacidade técnica e humana para realizar três entrevistas simultâneas. Essas entrevistas ocorreram durante os dois primeiros dias de atividade. Organização dos grupos para realização das entrevistas: foram formados três grupos para a realização de entrevistas simultâneas. Cada grupo foi formado por três pessoas, sendo dois alunos e um professor. O professor ficou responsável pela condução das entrevistas, enquanto os alunos se revezavam nas atividades de anotar palavraschave dos assuntos abordados pelo entrevistado e operar os equipamentos de gravação.

As entrevistas foram iniciadas com preâmbulo, feito pelo entrevistador, com as explicações dos objetivos da entrevista e a solicitação para que a pessoa entrevistada nos contasse: como foi à vida na Fazenda. De quais pessoas (personagens), objetos, fatos ou acontecimentos têm lembranças. Houve a preocupação de registrar claramente quando e onde se deram os acontecimentos e foi testada uma metodologia para levantamento dinâmico de palavras-chave, durante a ocorrência das entrevistas. Essa metodologia consiste em proceder à anotação das palavras-chave, ou "indexação" identificando, assim, os possíveis eixos temáticos, por um aluno, e outro aluno operava a gravação, enquanto o professor coordenava a entrevista. Houve uma orientação para não interromper o entrevistado, para tirar 
dúvidas sobre grafia ou descrições. Nos casos em que surgiram dúvidas dessa natureza elas foram sanadas ao término da entrevista.

Ao longo da entrevista, o "indexador" esteve atento as palavras que descreviam objetos, fatos e ações - sinalizando o contexto que tal conceito foi usado. Isto é, acrescentando um qualificador ao conceito identificado. Do mesmo modo que houve a orientação para a condução das entrevistas, o mesmo também foi feito no processo dinâmico de indexação dos conteúdos. Assim, o pesquisador colaborador, esteve presente no momento das entrevistas, e tomando nota das falas dos entrevistados, tomou nota de conceitos relacionados a:

a) Quando (data, períodos, épocas, etc.).

b) Onde (lugares, ambientes, regiões, espaços, etc.).

c) Quem (pessoas, personalidades, seres ou agentes de uma ação, etc.).

d) Porque (justificativas ou razões pelas quais ocorreram os fatos, acontecimentos, etc.).

e) O que (fatos, acontecimentos, atos, atitudes, etc.)

f) Como (processos, procedimentos, atividades realizadas, etc.).

O objetivo das entrevistas foi o de coletar descrições do cotidiano da fazenda, do dia a dia na perspectiva, principalmente, dos trabalhadores. Muitas práticas cotidianas, como falar, ler, circular, fazer compras ou preparar refeições, são do tipo tático. E, também, de modo mais geral, as "maneiras de fazer", os pequenos sucessos, as astúcias de "caçadores", as mobilidades da mão de obra, as simulações polimorfas e outros achados que provocam euforia, "tanto poéticos, quanto bélicos" (CERTEAU, 2009).

O primeiro desafio com qual nos deparamos foi: como construir as narrativas que nos tragam esse cotidiano? Pensamos, então, que poderíamos simplesmente apresentar o nosso objetivo para as pessoas. Dizer que gostaríamos de saber como era a vida na fazenda. Talvez a 
pessoa entrevistada saiba dessa vida não só por ela, mas também pelos relatos que os mais velhos faziam. O que ela traz via memória dos outros, também interessa. Como a pessoa introduz o relato é uma informação importante: é a escolha que ela faz, é a primeira imagem que the chega à mente a partir do estímulo recebido. Dessa maneira, precisamos estar atentos para estimular à narrativa. Lembrar que, se de um lado, o narrador é aquele que conduz a fala, por outro lado, a narrativa precisa de ouvidos que a escutem, senão a fala esmorece.

Os resultados dessa atividade de entrevistas foram muito surpreendentes tanto em relação aos conteúdos e conceitos revelados, ao logo das falas, quanto em termos de aproveitamento dos assuntos, emergidos com o emprego das anotações de palavras-chave. Esses assuntos serviram de orientação para se fazer buscas na literatura, como também nos instigaram na preparação dos preâmbulos e das perguntar que seriam feitas aos entrevistados vinham na sequência.

Outra atividade de pesquisa concomitante às entrevistas foi a observação e registro do espaço construído e da paisagem da Fazenda Santa Maria. Esta atividade se caracterizou por uma "caminhada" pela propriedade, incluindo o interior da casa sede e seu entorno imediato como jardins, pomares e outros espaços mais afastados como colônia, fragmentos de mata, córregos, vasca e outros.

Durante essa "caminhada" os participantes estiveram com todos os seus sentidos atentos e realizaram os levantamentos fotográficos, os desenhos de próprio punho, as filmagens e muitas descrições, registradas oralmente ou escrita, da materialidade e dos atrativos turísticos explorados e em potencial. Esta descrição foi pormenorizada e tecnicamente avaliada por meio de um "Inventário turístico da propriedade" realizado com um roteiro próprio montado pela equipe de turismo da UNESP (Campus de Rosana) sob a coordenação da professora Prof ${ }^{\mathrm{a}}$ Rosângela Custodio Cortez Thomaz que foi aplicado pela sua orientada de doutorado. A atividade de observação e registro do espaço construído e da paisagem foi desenvolvida sob a 
coordenação da profa. Anja Pratschke, que contou com a colaboração do prof. Paulo César Castral ambos pertencentes ao Instituto de Arquitetura e Urbanismo da USP/São Carlos.

\section{ANÁLISE E DISCUSSÃO DOS RESULTADOS ALCANÇADOS}

As entrevistas e os relatos sobre a vida cotidiana da Fazenda Santa Maria do Monjolinho foi o ponto de partida documentação da memória do local. A partir do processo de indexação dinâmico e presencial, feito durante 0 acompanhamento das entrevistas concedidas, foi possível analisar os conceitos extraídos das falas dos participantes, possibilitando a formação de eixos temáticos que posteriormente serviram para o desenvolvimento das etapas seguinte e organização das informações sobre a fazenda. Para tanto foram seguidas as ações: a) reunião de pesquisadores e os alunos pesquisadores colaboradores para discussão das temáticas identificadas; b) sistematização das temáticas em grandes grupos; c) conclusão dos eixos temáticos identificados. Os eixos temáticos foram: arte de fazer - entendido como o campo do trabalho de forma mais ampla, ou seja; tipo de produção - e sociabilidade - entendido como tipo de reunião entre pessoas motivadas pelo aprender fazer, lazer, festejos, religiosidade, entre outras. Por esses eixos perpassam as relações de espaço e de tempo. Este procedimento ocorreu durante o $2^{\circ}$ e $3^{\circ}$ dia de atividade e envolveu todos os participantes.

A atividade de transcrição das entrevistas se deu com base nos eixos temáticos definidos e possibilitou que fossem feitas somente as transcrições das partes das falas que continham conteúdos que colaboravam com o entendimento dos eixos temas selecionados. Esta atividade foi desenvolvida com a participação dos grupos de pesquisadores que realizaram as entrevistas e do grupo de pesquisadores que teve como meta a realização do trabalho de observação do espaço construído e da paisagem. As entrevistas foram 
transcritas de acordo com os eixos temáticos escolhidos e foram feitas as marcações do tempo e do local ao qual se referiam as falas e dos assuntos que eram tratados nas partes transcritas. $O$ resultado desta atividade serviu de base para a roteirização posterior do documentário sobre a fazenda enquanto produto resultante da pesquisa.

A partir dos eixos temáticos categorizados a partir das entrevistas, foi feito o levantamento documental sobre os assuntos dos eixos temáticos, feito no próprio acervo da fazenda. As principais fontes utilizadas foram: livros, periódicos, manuscritos, fotografias, receitas, etc. Esta atividade ocorreu no último dia e envolveu os grupos de entrevistas e da observação do espaço construído e da paisagem. $\mathrm{O}$ objetivo deste levantamento foi o de complementar, detalhar ou conferir maior veracidade ou exatidão as informações levantadas por meio de entrevistas.

Após os levantamentos complementares, foram feitas discussão para o planejamento ou elaboração de pré - roteiros para produção de documentário, momento em se discutiu a sequência de desenvolvimento das categorias ou sub-temas temas que deram origem aos documentários de curta duração (no mínimo 1 e no máximo 4 temas). 0 procedimento adotado foi o de partir da definição dos eixos temáticos temas arte de fazer, sociabilidade, juntamente com o conjunto dos subtemas passaram a correspondem às questões quem (pessoas, personalidades, seres ou agentes de uma ação, etc.) e o que (fatos, acontecimentos, atos, atitudes, etc.), perpassadas pelas categorias de tempo quando (data, períodos, épocas, etc.) e de espaço onde (lugares, ambientes, regiões, espaços em que se passam os acontecimentos etc.). Esses conteúdos são frutos das entrevistas, acrescidos da pesquisa documental e da observação do espaço construído e da paisagem e se constituiu em uma matéria- prima preciosa a qual se adiciona nos casos em que houve pertinência alguma explicação técnica de especialistas, dos proprietários ou outro ator envolvido na atividade em atendendo a questão porque (justificativas ou razões pelas quais 
ocorreram os fatos, acontecimentos, etc.) e, às vezes, o como (os processos, procedimentos, atividades foram realizados, etc.) completando, assim, o rol de expectativas, criadas inicialmente. Esta atividade ocorreu durante $03^{\circ}$ e $4^{\circ}$ dia e envolveu todos os participantes.

Com coordenação de todos os docentes envolvidos e em colaboração com os alunos participantes, de graduação e pósgraduação, foram desenvolvidas as atividades de organização e disponibilização de todos os documentos, imagens, vídeos das entrevistas no Google Docs, para discussão coletiva sobre a produção do documentário.

Para as atividades de edição fizemos uso dos recursos tecnológicos, disponíveis nas universidades locais (USP e UFSCar). Esta atividade ficou sob a responsabilidade dos técnicos em Informática José Eduardo Zanardi e Evandro César Bueno dos Laboratórios de Midimagem e de Ensino Informatizado do IAU/USP. Os produtos decorrentes desta atividade vão contribuir com o trabalho educacional realizado nesta fazenda pelos atuais proprietários. $O$ detalhamento metodológico, aqui relatado, tem por objetivo facilitar a avaliação da atividade e possibilitar as adequações necessárias para propor a sua realização em outras fazendas, integrantes deste projeto.

\section{CONSIDERAÇÕES FINAIS}

A relevância desse projeto reside também na formação de profissionais competentes tecnicamente, éticos e comprometidos com as causas da cultura e da preservação do patrimônio histórico. A oportunidade de contato com a realidade instiga o espírito investigativo, engajado com problemas concretos e, assim, faz avançar uma área de conhecimento que carece de reflexões teóricas e metodológicas apropriadas e inovadoras. 
Outro aspecto a destacar é a relevância social desse projeto que pode gerar contribuições, desde as mais tangíveis e imediatas, como é o caso da sensibilização das comunidades locais para a valorização de seu próprio patrimônio histórico, a partir de um olhar externo (experts em áreas especializadas), até aquelas que só serão percebidas a médio e longo prazos, como é o caso da formação de consciência crítica e desenvolvimento de atitudes favoráveis à valorização e preservação do patrimônio cultural, além da sensibilização do poder público local para a incorporação de políticas públicas, permitindo subsídios a ações preservacionistas do CONDEPHAAT e de políticas municipais voltadas à proteção do patrimônio cultural regional.

Temos, notadamente, um sujeito a priori que construiu conhecimentos, que por sua vez foram reconstruídos por novos sujeitos que, em momentos diferentes, foram seus usuários. A nossa intenção, ao propormos parâmetros voltados a uma sistematização parcial (e ao mesmo tempo aberta e relacional) dos conhecimentos que circundam os ambientes das Fazendas históricas paulistas é, justamente, o de otimizar ou aperfeiçoar a sua própria produção e uso pela sociedade. Nesse momento, a intuição de que, ao aproximarmos diferentes formas de coleta de conceitos e significados, possamos chegar a uma proposta não só inovadora, mas consistente para uma sistematização possível dos conhecimentos gerados e em geração relacionados a essas fazendas.

$\mathrm{E}$, tendo em vista os avanços dos trabalhos já desenvolvidos na esfera desta pesquisa por diferentes áreas que se inter-relacionam, inclusive a partir do universo das fazendas, é que conjecturamos tomar como ponto de partida a estruturação mnemônica da base dados já elaborada para sistematização dos conhecimentos das fazendas e fazermos a articulação e o movimento de registro, organização, recuperação, uso e reconstrução mediados por uma rede conceitual dinâmica (em configuração), que por sua vez, poderá ser mediada por 
um terceiro sujeito, responsável pelos ajustes indiretos e subjetivos necessários no trato com o conhecimento.

Enfim, vislumbra-se poder, minimamente, identificar e estruturar de modo fundamentado, um veículo de facilitação comunicativa que possibilite e potencialize a geração e uso do conhecimento, sem interferência de barreiras hierárquicas e políticas em seu arranjo, e que sirvam especialmente para o trato com os conhecimentos vinculados a um modo de vida.

A superação de questões terminológicas, viabilizando a interoperabilidade semântica dos conteúdos e metadados disponibilizados, e a solução nos processos de intercâmbio de informação, por meio de formatos de padrões para troca de dados são aspectos focados como pontos de investigação.

É esperado que o uso da metodologia proposta resulte num modelo de inventário que sirva de base para o desenvolvimento de um sistema web livre, o "Memória Virtual Rural", com a utilização de tecnologias mediadoras que possam contribuir para que as informações, hoje isoladas, possam ser disponibilizadas e utilizadas de forma integrada.

Uma base de dados estruturada a partir de parâmetros mínimos de sistematização de uso da linguagem tem resultados substanciais no que diz respeito à produção e à divulgação dos conhecimentos que nela são disponibilizados.

O detalhamento metodológico, aqui relatado, tem por objetivo facilitar a avaliação da atividade e possibilitar as adequações necessárias para propor a sua realização em outras fazendas, integrantes deste projeto.

Finalmente, cabe registrar que no universo das fazendas históricas paulistas, as possibilidades não se esgotam, uma vez que encontramos um território promissor com grande amplitude de atuação no sentido da descoberta da diversidade de bens patrimoniais raros e de 
valor inestimável, do ponto de vista do patrimônio histórico, cultural e natural.

Espera-se, ainda que os resultados de pesquisas voltadas para o patrimônio histórico resultem em informações capazes de contribuir para revelar o passado, compreender o presente e trazer inovação para o desenvolvimento humano do futuro, pois esse patrimônio tem mostrado a sua importância como elemento de formação de identidade, de cidadania e de pertencimento a um determinado contexto espaçotemporal.

\section{REFERÊNCIAS}

CAMPOS, Ernesto Souza; LEME, Ernesto. No limiar da academia paulista de letras. São Paulo: Saraiva, 1964.

CAMPOS, Ernesto Souza. Meio século de trabalho. São Paulo: Saraiva, 1998.

CERTEAU, Michel De. A invenção do cotidiano: artes de fazer. Petrópolis: Vozes, 2009. v. 1.

SANTOS, B. S. A crítica da razão indolente: contra o desperdício da experiência. São Paulo: Cortez. 2000.

THOMPSON, Paul. A voz do passado: história oral. Rio de Janeiro:

Paz e Terra, 1992.

\section{Title}

Rural historic heritage registration from oral history

\section{Abstract}

Introduction: Describes research activities carried out on a historic farm in the state of São Paulo, Brazil, in order to record intangible cultural heritage for the documentation and preservation of rural social memory.

Objective: To collect oral history on the lifestyles of historic farms in the interior of the state of São Paulo in order to preserve and disseminate this intangible heritage. 
Methodology: For data collection, personal interviews were conducted with ten former residents, employees and owners of the Santa Maria Monjolinho Farm, using the oral history methodological approach, with theoretical support guided by Ranganathan's work.

Results: The interviews were tabulated and analyzed and the results were used for the production of a documentary covering the livelihoods of the rural community.

Conclusion: It is concluded that it was possible to raise awareness of local communities for the recovery of their own heritage, stimulate the formation of critical awareness and develop attitudes favorable to the recovery and preservation of cultural heritage. It was also confirmed that actions involving the collection, recording and dissemination of national heritage can raise awareness in the medium term, and amongst governmental bodies in order to formulate policies for the protection of cultural heritage.

Key-Word: History heritage. Historic farm. Oral history.

\section{Titulo}

Registro del patrimonio histórico rural a partir de la historia oral

\section{Resumen}

Introducción: Describe la actividad desarrollada en hacienda histórica del interior del estado de São Paulo, con el fin de registrar los bienes culturales inmateriales para la documentación y preservación de la memoria social rural.

Objetivo: Investigar la historia oral sobre los estilos de vida en las haciendas históricas del interior de São Paulo con el fin de preservar e difundir este patrimonio intangible.

Metodología: Para recoger los datos, las entrevistas fueron desarrolladas desde el enfoque metodológico de la historia oral, con el apoyo teórico basado en S. Ranganathan, con diez habitantes antiguos, empleados y propietarios de la Hacienda Santa Maria do Monjolinho.

Resultados: Las entrevistas fueron tabuladas e analizadas, y los resultados fueron utilizados para la producción de un documental sobre los modos de vida de la población rural.

Conclusión: Se puede concluir que fue posible promover la sensibilidad de las comunidades locales para la valoración de su propio patrimonio histórico; estimular la formación de la conciencia crítica e incentivar actitudes que valoren la preservación del patrimonio cultural; y comprobar que hacer el registro del patrimonio histórico puede sensibilizar también, al medio plazo, el poder público para la incorporación de políticas de protección del patrimonio cultural.

Palavras clave: Patrimonio histórico. Hacienda histórica. Historia oral.

Recebido em: 21/03/2015

Aceito em: 31/07/2015 